\title{
Decarboxylation of Metastable Methyl Benzoate Molecular Ions
}

\author{
Noémie Dechamps, Robert Flammang, and Pascal Gerbaux \\ Laboratory of Organic Chemistry, University of Mons-Hainaut, Mons, Belgium
}

Pham-Cam Nam and Minh-Tho Nguyen

Department of Chemistry, University of Leuven, Leuven, Belgium

\begin{abstract}
By using a combination of mass spectrometric methodologies and density functional theory calculations [DFT/B3LYP/6-311 ++ G(d, p)], it is proposed that the decarboxylation of metastable methyl benzoate molecular ions occurs via distonic and ion-neutral complex (INC) intermediates. The same INC involving a complex between the benzyl radical and protonated carbon dioxide is also generated upon decarboxylation of metastable phenylacetic acid molecular ions. Internal proton transfer within the INC produces in fine a mixture of toluene and isotoluene radical cations. (J Am Soc Mass Spectrom 2006, 17, 807-814) (c) 2006 American Society for Mass Spectrometry
\end{abstract}

$\mathrm{T}$ The elimination of small, stable, and neutral molecules is classically observed in the gas-phase fragmentation of several organic molecular ions [1]. These reactions are referred to as rearrangement reactions as they transform an initial odd-electron species into a final odd-electron fragment. Among these reactions, the loss of carbon dioxide has been reported on several occasions, but we would like to limit ourself in this short introduction to one famous example, the decarboxylation of ionized glycolic acid [2] (Scheme 1).

The collisional activation (CA) spectrum of the $\left[\mathrm{C}, \mathrm{H}_{4}, \mathrm{O}\right]^{+}$ions (loss of $\mathrm{CO}_{2}$ ) of glycolic acid features intense peaks at $\mathrm{m} / \mathrm{z} 18$ and 14 (ionized water and methylene, respectively), that are not significantly seen in the corresponding spectrum of methanol molecular ions. Furthermore, these ions give rise to a very strong charge-stripping peak, whereas ionized methanol does not. Quantum chemical calculations indicated that the distonic ions (Scheme 1) are of higher stability and protected against isomerization by a considerable energy barrier [2]. Mechanistic details have been reported elsewhere [3].

It has also been reported in 1990 that distonic ions were generated during the fragmentation of metastable methyl benzoate molecular ions. Among these fragmentations, the loss of carbon dioxide was clearly observed, but the authors "refrain themselves to suggest a particular reaction pathway" [4]. In the present study, we set out to reconsider this quite peculiar reaction by using experimental metastable ion characteristics and exten-

Published online April 17, 2006

Address reprint requests to Dr. P. Gerbaux, Laboratory of Organic Chemistry, University of Mons-Hainaut, Avenue Maistriau 19, B-7000 Mons, Belgium. E-mail: pascal.gerbaux@umh.ac.be sive theoretical calculations. The main purpose of the combined study is to find out a reaction mechanism that can interpret the experimental findings.

\section{Experimental}

The spectra were recorded on a large-scale tandem mass spectrometer (Waters AutoSpec 6F, Manchester, $\mathrm{UK}$ ) combining six sectors of $\mathrm{cE}_{1} \mathrm{~B}_{1} \mathrm{CE}_{2} \mathrm{qcE}_{3} \mathrm{~B}_{2} \mathrm{CE}_{4}$ geometry $\left(E_{i}\right.$ stands for electric sector, $B_{i}$ for magnetic sector, $\mathrm{q}$ for a quadrupole collision cell and $\mathrm{c}$ for conventional collision cells). Typical conditions have been reported elsewhere [5]: $200 \mu \mathrm{A}$ trap current in the electron ionization mode and $1 \mathrm{~mA}$ emission current in the chemical ionization mode.

The installation of the rf-only quadrupole collision cell ( $Q$ cell) inside the instrument between $E_{2}$ and $E_{3}$ has also been reported [6]. The products of dissociation of metastable ions within the quadrupole (without collision gas) can be recorded by scanning the field of the second magnet; this kind of spectra will be referred to in the text as "resolved" MIKE spectra. Collisional activation of metastably generated ions within the quadrupole was obtained by selecting the ions of interest with $\mathrm{B}_{2}$ and scanning the field of $\mathrm{E}_{4}$.

Kinetic energy release measurements have been performed by scanning the field of $E_{2}$ collecting the ions

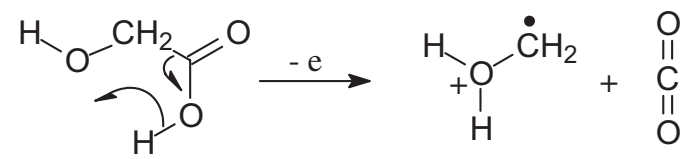

Scheme 1 
Table 1. "Resolved" MIKE spectra of various 4-substituted methyl benzoate molecular ions

\begin{tabular}{|c|c|c|c|c|c|c|c|c|}
\hline \multirow{3}{*}{$\begin{array}{c}\text { Precursor } \\
\text { Me Benzoates }\end{array}$} & \multicolumn{8}{|c|}{ Relative intensity ${ }^{a}$} \\
\hline & \multicolumn{8}{|c|}{ Neutral lost } \\
\hline & $\mathrm{H} \cdot$ & $\mathrm{CH}_{3}$. &. $\mathrm{OH}$ & $\mathrm{H}_{2} \mathrm{O}$ &. $\mathrm{OCH}_{3}$ & $x \cdot$ & $\cdot \mathrm{CO}_{2} \mathrm{CH}_{3}$ & $\mathrm{CO}_{2}$ \\
\hline$p-\mathrm{NO}_{2}$ & 8 & - & 100 & - & - & - & - & - \\
\hline$p-\mathrm{CN}$ & 100 & - & - & - & - & - & - & 8 \\
\hline$p-\mathrm{COOCH}_{3}$ & 6 & $100^{\mathrm{b}}$ & - & - & 30 & - & 16 & - \\
\hline$p-\mathrm{Br}$ & 80 & - & - & - & 100 & 85 & - & - \\
\hline$p-\mathrm{Cl}$ & 100 & - & - & - & 43 & 37 & - & - \\
\hline$p-1$ & 0 & - & - & - & 100 & 30 & - & - \\
\hline$p-\mathrm{F}$ & 100 & - & - & - & 6 & - & - & 3 \\
\hline$H$ & 52 & - & - & 5 & - & - & - & 100 \\
\hline$p-\mathrm{OCH}_{3}$ & 14 & - & - & - & 100 & - & - & - \\
\hline$p-\mathrm{NH}_{2}$ & 9 & - & - & - & 100 & - & - & - \\
\hline
\end{tabular}

apeaks less than $5 \%$ not included.

${ }^{\mathrm{b}} \mathrm{CH}_{4}$ loss (m/z 178 ions): $6 \%$.

with an off-axis photoelectron multiplier detector after mass-selection of the $m / z 136$ ions by $E_{1}$ and $B_{2}$.

Most of the samples were commercially available and used in this work without any further purification except for some substituted benzoates and labeled benzoates prepared by conventional procedures.

Quantum chemical calculations were carried out using the Gaussian 03 set of programs [7]. Geometry optimizations of the stationary points including methyl benzoate radical cation and its isomers and the corresponding transition structures (TS) connecting the relevant equilibrium structures were conducted at the UB3LYP/6-311 ++ G(d,p) level of density functional theory. The identities of the local minima and TS have been established by harmonic vibrational frequency calculations. In several cases, intrinsic reaction coordinate (IRC) calculations were performed to ascertain the connection between a TS and two local minima. Unless otherwise noted, relative energies on the potential energy surfaces were obtained from UB3LYP/6-311 ++ $\mathrm{G}(\mathrm{d}, \mathrm{p})+$ ZPE calculation, and given in $\mathrm{kJ} \mathrm{mol}^{-1}$.

\section{Results and Discussion}

\section{Metastable Ion Characteristics}

The major dissociation channel in the $70 \mathrm{eV}$ electron ionization mass spectrum of methyl benzoate consists, as expected [8], of the loss of a methoxyl radical followed by decarbonylation of the so-formed benzoyl cations (sequence $m / z 136 \rightarrow 105 \rightarrow 77$ ). This classical chemistry is, however, strongly modified if metastable molecular ions are sampled. In this particular energy window, decarboxylation becomes the main dissociation process $(100 \%)$ beside a hydrogen atom loss (52\%) and a water loss (5\%), cf. Table 1 and references [4] and [9].

A quite similar behavior was noticed for the isomeric molecular ions of phenylacetic acid that, under $70 \mathrm{eV}$ EI conditions, suffer a single bond $\mathrm{CH}_{2}-\mathrm{CO}_{2} \mathrm{H}$ cleavage $(\mathrm{m} / \mathrm{z} 91,100 \%)$ but as far as the corresponding metasta- ble molecular ions are concerned, quasi specifically (96\%) rearrange into $\mathrm{C}_{7} \mathrm{H}_{8}^{++}$radical cations upon loss of carbon dioxide. It is worthy of note that a hydrogen atom loss $(1 \%)$ is not significantly seen in this case [9].

Kinetic energy release measurements have also frequently been used in the past for ion structure characterization [10]. Peak shape analysis performed on the metastable peaks for $\mathrm{CO}_{2}$ losses from methyl benzoate and phenylacetic acid ion isomers affords the following values:

Methyl benzoate $\left(\mathrm{PhCO}_{2} \mathrm{CH}_{3}\right): \mathrm{T}_{50}=133 \mathrm{meV} ; \mathrm{T}_{22}=$ $279 \mathrm{meV} ; \mathrm{T}_{22} \div \mathrm{T}_{50}=2.1$

Phenylacetic acid $\left(\mathrm{PhCH}_{2} \mathrm{CO}_{2} \mathrm{H}\right): \mathrm{T}_{50}=130 \mathrm{meV} ; \mathrm{T}_{22}$ $=272 \mathrm{meV} ; \mathrm{T}_{22} \div \mathrm{T}_{50}=2.1$

Within the experimental errors, it is thus assumed that the corresponding metastable molecular ions losing $\mathrm{CO}_{2}$ exhibit the same structure and follow a single mechanism as the measured ratios $\mathrm{T}_{22} \div \mathrm{T}_{50}$ do not deviate significantly from 2.16 [11].
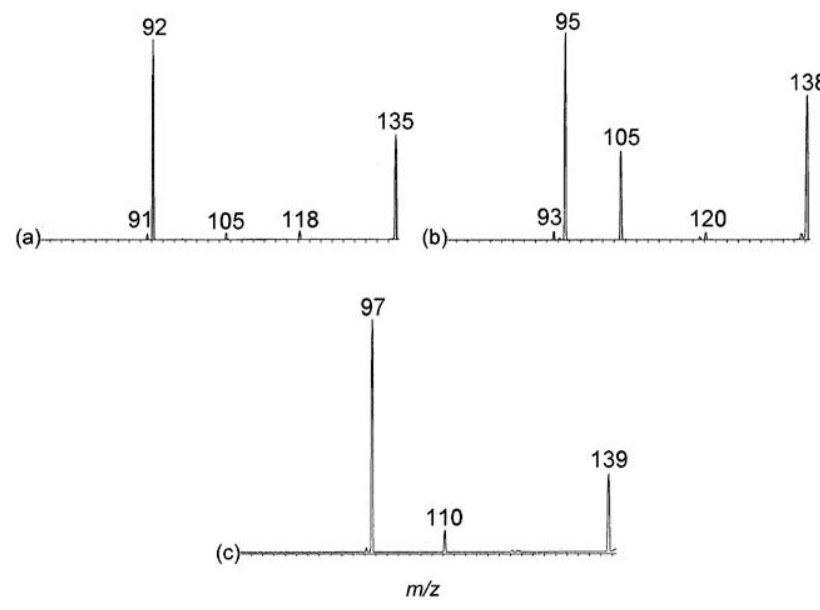

Figure 1. "Resolved" MIKE spectra of the molecular ions of methyl benzoate $\mathbf{1}(\mathrm{m} / \mathrm{z} 136)$ (a); methyl- $d_{3}$ benzoate $\mathbf{1}_{d 3}(\mathrm{~m} / \mathrm{z} 139)$ (b); methyl benzoate- $d_{5} \mathbf{1}_{d 5}(\mathrm{~m} / \mathrm{z}$ 141) (c). 
<smiles>CCC(=[OH+])OC</smiles>

1

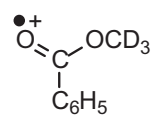

$1_{d 3}$

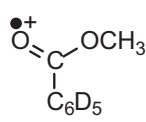

$1_{d 5}$<smiles>C[C+](O)[C+][O+]</smiles>

2<smiles>O[C+](O)c1ccccc1</smiles>

$3_{d}$<smiles>CO[C+](O)C[18O]</smiles>

$3_{d 5}$

Scheme 2

\section{Substituent Effects}

Substituent effect on reaction kinetics is a usual way of shedding some light into mechanistic details of aromatic substrate reactivity [12]. We have thus evaluated these effects by means of the "resolved" MIKE spectra of various 4-substituted methyl benzoate molecular ions (cf. Table 1). The principal observation is a significant decrease (or even disappearance) of the decarboxylation process for all substituted methyl benzoates, the main reaction, thus, becoming either a single bond cleavage (methoxyl loss) or a hydrogen atom loss depending on the nature of the substituent. Moreover, some unexpected results were also noticed. For instance, the metastable methyl radical loss for dimethyl terephthalate (entry 3 in Table 1), or the hydroxyl radical loss for methyl 4-nitrobenzoate (entry 1 in Table 1) show some novel features. In the light of the results presented in this report, some of these "unusual" fragmentations can readily be explained and will be discussed in a forthcoming paper [13].

We have also recorded the MIKE spectrum of the metastable molecular ions of ethyl benzoate: the chemistry of these metastable ions exhibits here a new reaction channel, namely the loss of ethene, which is a typical reaction of ionized ethyl esters. Decarboxylation, together with loss of $\mathrm{C}_{2} \mathrm{H}_{4} \mathrm{O}$, is also detected, but does not constitute the most competitive process [ $\mathrm{m} / \mathrm{z}(\%): 149$ (100), 135 (1), 132 (8), 122 (100), 106 (29), 105 (24), 91 (3)].

\section{Deuterium Labeling Experiments}

The unimolecular dissociations of metastable ion $\mathbf{1}^{++}$ and two isotopomers, $\mathbf{1}_{d 3}^{+}$and $\mathbf{1}_{d 5}^{+}$, are compared to each other in Figure 1. A couple of important indications arise from these spectra. First, the loss of carbon dioxide, not an isobaric $\mathrm{C}_{2} \mathrm{H}_{4} \mathrm{O}$ species, is accompanied by a
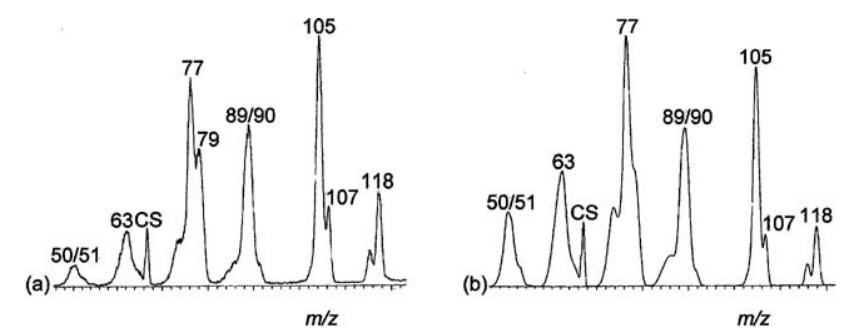

Figure 2. (a) MS/MS/MS spectrum (oxygen collision gas) of the $\mathrm{m} / \mathrm{z} 135$ ions prepared by metastable $\mathrm{H}^{\cdot}$ loss from ionized methyl benzoate $(\mathrm{m} / \mathrm{z}$ 136) and (b) CA spectrum (oxygen collision gas) of $[\mathrm{M}+\mathrm{H}]^{+}$ions (methanol chemical ionization) of phthalide (MW 134). significant isotope effect. Such an isotope effect can be detected by considering the relative intensities of peaks at $m / z$ 92, 95, and 105 in the spectra, (cf. Figure 1a and b), and assuming that the loss of a methoxyl radical is probably not affected by deuterium incorporation in the methyl group. Accurate quantification of this isotope effect is, however, delicate as these two reactions $\left(\mathrm{CO}_{2}\right.$ and $\mathrm{C}, \mathrm{H}_{3}, \mathrm{O}$ losses) are certainly characterized by very different frequency factors; (Scheme 2).

Such a primary isotope effect indicates that a hydrogen migration from the methyl group is occurring in the rate-determining step of the decarboxylation reaction. A reasonable candidate for the ions generated in such conditions is likely to be the distonic species $3^{+}$. Experimental and theoretical evidences for the production of such a distonic structure have been presented in previous studies $[4,9]$. A second interesting indication is that the loss of a hydrogen atom arises quasi-exclusively from the benzenic ring and not from the methyl group.

\section{Metastable Hydrogen Atom Loss}

As mentioned above, the loss of one hydrogen atom $(\mathrm{m} / \mathrm{z}$ 135 ) is the second important dissociation pathway of the metastable methyl benzoate ions. The unimolecular chemistry of these ions generated from phthalates has already been discussed on several occasions [14-16]. As competition with the loss of $\mathrm{CO}_{2}$ is observed in the narrow metastable energy window, critical energies for the two reactions must be very similar to each other. This loss has also been observed for the distonic ions $3^{+}$, but is not significantly detected for phenylacetic acid ions $\mathbf{2}^{+}$.

Isotope labeling shows that the hydrogen elimination mainly originates from the phenyl ring in the case of methyl benzoate ions $\mathbf{1}^{++}$(shown by the MIKE spectra of ions $\mathbf{1}_{d 3}^{+}$and $\mathbf{1}_{d 5}^{+}$); the same holds true for the distonic ions $3^{++}$(shown by the MIKE spectra of ions $3_{d}^{++}$and $3_{d 35}^{+}$). As for the $\mathrm{CO}_{2}$ loss, a primary isotopic effect is qualitatively observed when comparing the $\mathrm{H}^{-}$loss from $\mathbf{1}^{++}$and $\mathbf{1}_{d 3}^{+}$.

The CA spectrum of the $m / z 135$ ions generated from metastable methyl benzoate molecular ions is shown in

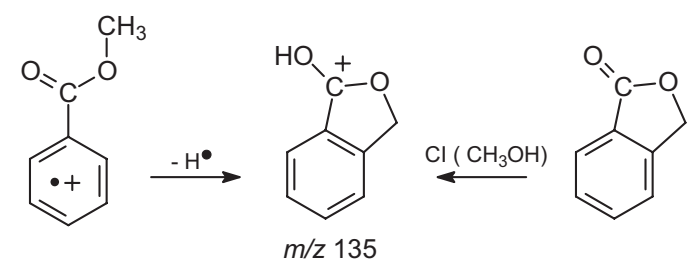

Scheme 3 


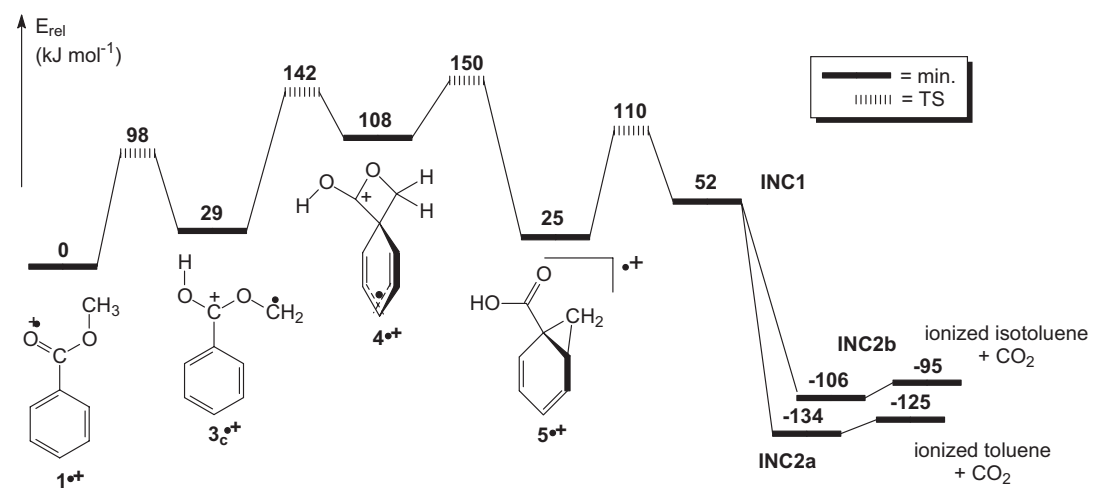

Figure 3. Potential energy surface for the intramolecular process occurring at the ipso position. Relative energies given in $\mathrm{kJ} \mathrm{mol}^{-1}$ were determined from UB3LYP/6-311 + $+\mathrm{G}(\mathrm{d}, \mathrm{p})+\mathrm{ZPE}$ calculation.

Figure 2, and compared with the corresponding spectrum of protonated phthalide generated by chemical ionization (methanol reagent gas) of phthalide, see Scheme 3. The proton affinity of phthalide has been theoretically [B3LYP/6-311 + + G(d,p)] estimated in the present work to be about $862 \mathrm{~kJ} \mathrm{~mol}^{-1}$ for the carbonyl oxygen site, $798 \mathrm{~kJ} \mathrm{~mol}^{-1}$ for the di-coordinated oxygen site and $712 \mathrm{~kJ} \mathrm{~mol}^{-1}$ for the benzene ring. These values allow us to attach the proton on the carbonyl oxygen.

The close analogy between the CA spectra of metastable methyl benzoate ions and protonated phthalide points out that the loss of hydrogen is not a single bond cleavage of a $\mathrm{C}-\mathrm{H}$ bond of the benzene ring, but it rather takes place in a more complex multi-step process and that is supported by theoretical calculations indicating that the methoxycarbonyl phenyl cation plus $\mathrm{H}^{\text {. }}$ is too high in energy to allow competition with the carbon dioxide loss (vide infra).

\section{Quantum Chemical Calculations}

Metastable $\mathrm{CO}_{2}$ loss

(A) CYCLIZATION AT THE IPSO POSITION. In an attempt to understand the mechanism of the decarboxylation process described above in the preceding experimental section, and because the ultimate products of reaction were previously identified as a mixture of toluene and isotoluene radical cations [17], the most direct mechanism considered could be the one given in Scheme 4.

In this scheme, it is proposed that the conventional radical cation $\mathbf{1}^{++}$is isomerized into a distonic rotamer $3 c^{-+}$, see reference [9], which undergoes an intramolecular ipso substitution similar to the ipso attack of $\sigma$-radicals on aromatics bearing suitable leaving groups [18]. Cleavage of the cyclobutane ring could thereafter produce an ion neutral complex (INC) involving proton-

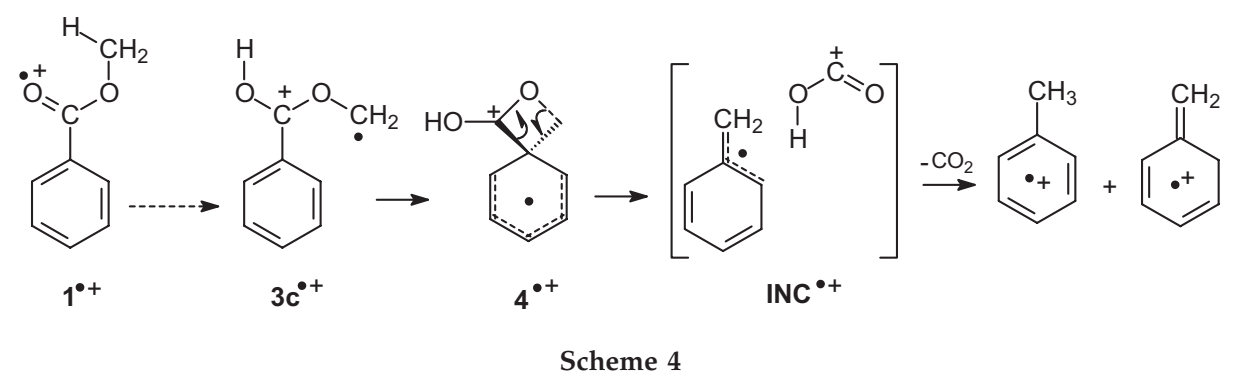<smiles>COC(O)c1ccccc1</smiles>

3a cis-trans

$8 \mathrm{~kJ} \mathrm{~mol}^{-1}$<smiles>CCOC(O)c1ccccc1</smiles>

3b cis-cis

$21 \mathrm{~kJ} \mathrm{~mol}^{-1}$<smiles>COC(O)c1ccccc1</smiles>

3c trans-cis

$29 \mathrm{~kJ} \mathrm{~mol}^{-1}$<smiles>[CH2]O[C@H](O)c1ccccc1</smiles>

3d trans-trans

$42 \mathrm{~kJ} \mathrm{~mol}^{-1}$ 


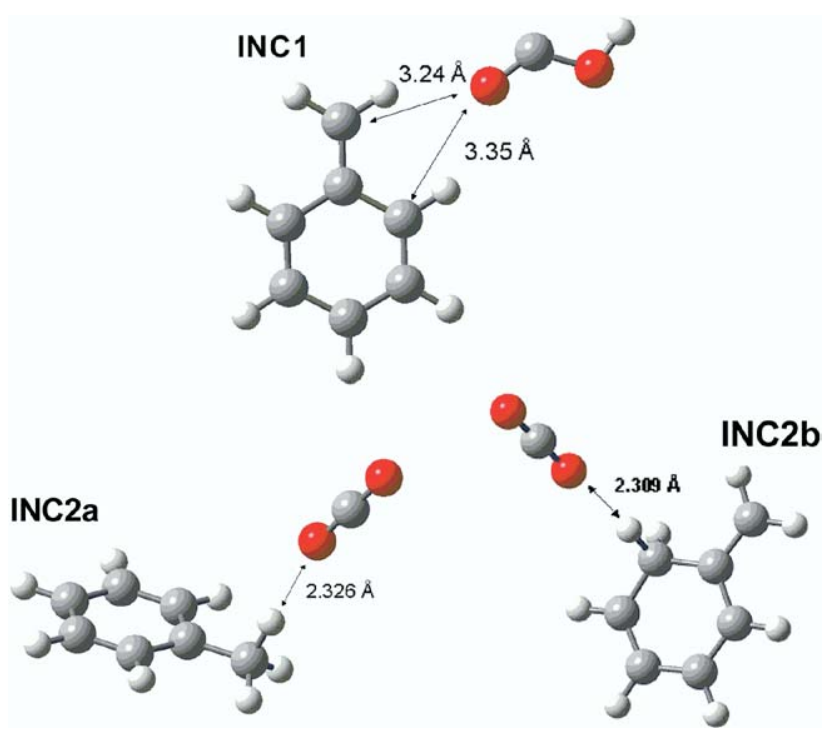

Scheme 6

ated carbon dioxide capable to deliver a proton to both sites of a benzyl radical [17].

Figure 3 displays the theoretically estimated relative energies of the different structures that are likely involved in the overall decarboxylation process of ionized methylbenzoate.

Starting from metastable ion $\mathbf{1}^{++}$, the initial hydrogen migration takes place when a methyl hydrogen atom shifts to the carbonyl oxygen thus creating a distonic ion $3 \mathbf{b}^{++}$through a transition-state (TS) of about $98 \mathrm{~kJ}$ $\mathrm{mol}^{-1}$. The distonic ion $3 \mathbf{b}^{-+}$has in fact several different conformations generated by separate or subsequent rotations around the $\mathrm{O}-\mathrm{H}$ and the other $\mathrm{O}-\mathrm{CH}_{2}$ single bonds, see Scheme 5. Only one of these rotamers, $3 c^{-+}$, which is directly related to the global mechanism of decarboxylation of ionized methyl benzoate is shown in Figure 3. For the sake of simplicity, the other rotamers are not included as the required rotational TS energies are calculated lower than $98 \mathrm{~kJ} \mathrm{~mol}^{-1}$ (around $60 \mathrm{~kJ} \mathrm{~mol}^{-1}$ ).

As depicted in Scheme 4 and Figure 3, the methylene radical center of the rotamer $3 c^{-+}$lies in an adequate position to attack the ipso position of the benzene ring resulting into a spiranic ionized intermediate $4^{+}$. The energy barrier for this radical addition reaction is $142 \mathrm{~kJ}$ $\mathrm{mol}^{-1}$, a value larger than the energy barrier for the previous hydrogen migration $\left(\mathbf{1}^{++} / 3 \mathbf{b}^{-+}\right)$. This is, however, not completely in contradiction with the experimentally observed isotope effect, as in multi-step pro- cesses, all kinetic constants of the individual steps preceding the rate-determining step appear in the observed kinetic constant.

Following the ipso attack, the spiranic intermediate could proceed further by various ring cleavages to new radical cations. Among these, the norcaradiene structure $5^{+}$calculated previously only $25 \mathrm{~kJ} \mathrm{~mol}^{-1}$ less stable than ionized methyl benzoate [9] is actually an interesting candidate initiated by cleavage of the $\mathrm{O}-\mathrm{CH}_{2}$ bond in $4^{-+}$. This process requires an activation energy of about $150 \mathrm{~kJ} \mathrm{~mol}^{-1}$. The $5^{++}$ions link to the ion-neutral complex INC1 through a bond breaking transition structure, which has a relative energy of 110 $\mathrm{kJ} \mathrm{mol}{ }^{-1}$ with respect to the reference $\mathbf{1}^{++}$ions.

Proton transfer within the INC1 complex finally affords the products (ionized toluene, ionized isotoluene, and carbon dioxide) via INC2a,b. The calculated structures of the INC complexes are indicated in Scheme 6 . Although we suspect their existence, we were not able to find out transition structures linking INC1 complex to INC2a and/or INC2b (vide infra).

(B) CYCLIZATION AT THE ORTHO POSITION. Obviously, it can be recognized that there is also another possibility for the $\mathrm{CH}_{2}$ terminal radical group attacking the ring. Upon formation of $3 \mathrm{c}^{+}$, the methylene end can indeed attack the ortho position of the benzene ring. We have, therefore, examined this reaction pathway to clarify the mechanism of $\mathrm{CO}_{2}$ elimination. It turns out that this mechanism, depicted in Scheme 7, accounts more accurately for most experimental observations.

Figure 4 shows the potential energy profile based on an ortho interaction of the terminal methylene with the ring. In this mechanism, a new hemiacetal radical cation $6^{+}$is formed and calculated more stable than the distonic precursor ion $3 \mathrm{c}^{+}$by an amount of $60 \mathrm{~kJ} \mathrm{~mol}^{-1}$. The energy barrier connecting $3 \mathrm{c}^{++}$to $\mathbf{6}^{++}$is of $59 \mathrm{~kJ}$ $\mathrm{mol}^{-1}$. Such a barrier height is not large and implies that once $3 \mathrm{c}^{++}$is created, $\mathbf{6}^{++}$is more easily accessible than the $4^{+}$ion which was involved in the previous mechanism (Figure 3). This is in keeping with the predicted relative stabilities of the intermediate ions. In $6^{+}$, the positive charge is certainly stabilized by the electron lone pairs of the two oxygens and the radical centre can be fully delocalized over the ring double bonds; similar electronic effects are also expected for $4^{+}$ but ring strain effects [19] will certainly destabilize this ion compared to $6^{+}$.

In going along with this rearrangement and fragmentation process, hydrogen atom at the ortho site of $6^{+}$

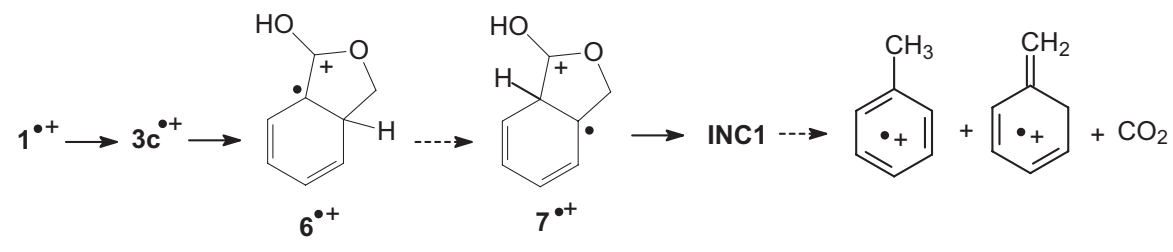




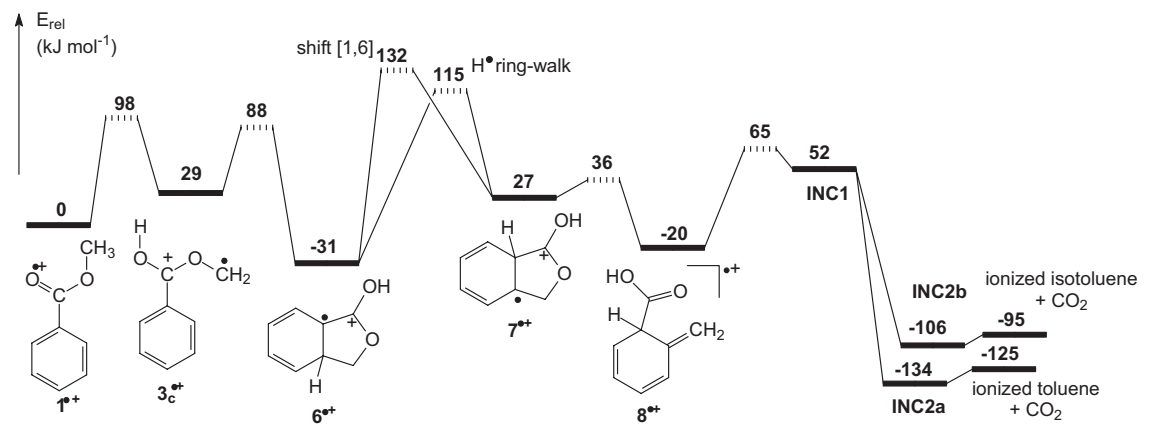

Figure 4. Potential energy surface for an intramolecular process occurring at the ortho position. Relative energies given in $\mathrm{kJ} \mathrm{mol}^{-1}$ were determined from UB3LYP/6-311 ++ G(d,p) + ZPE calculation.

is rearranged to form $7^{+}$. For this step, there are two possibilities. The first is a process in which the hydrogen at the ortho carbon of the six-membered ring directly shifts to the ipso position [cf. TS shift $(1,6)$ in Figure 4]. The associated energy barrier of this hydrogen migration amounts to $132 \mathrm{~kJ} \mathrm{~mol}^{-1}$. The second possibility involves a ring walk [20, 21] of hydrogen around the benzene ring. Hydrogen atom goes, thus, by multiple migration steps. Five steps for the hydrogen ring walk are shown in some details in Scheme 8. In fact, the largest calculated barrier height for this hydrogen migration amounts to $115 \mathrm{~kJ} \mathrm{~mol}^{-1}$ (cf. TS ring-walk in Figure 4).

An opening of the five-membered ring in $7^{+}$produces the $8^{+}$ions with a rather small activation energy of $9 \mathrm{~kJ} \mathrm{~mol}{ }^{-1}$. It appears obvious from Figures 3 and 4 that the mechanism of ortho attack is more favored than that at the ipso position, but a barrier height of $115 \mathrm{~kJ}$ $\mathrm{mol}^{-1}$ (ortho attack) or certainly $142 \mathrm{~kJ} \mathrm{~mol}^{-1}$ (ipso attack) appear too high to allow competition with a single bond cleavage generating a benzoyl cation plus a methoxyl radical, $109.5 \mathrm{~kJ} \mathrm{~mol}^{-1}$ from reference [22].

(C) ORTHO SUBSTITUTION FOLLOWED BY C-O BOND CLEAVAGE. We have therefore considered another mechanism differing from the previous one by $\mathrm{C}-\mathrm{O}$ bond cleavage following the ortho attack and preceding

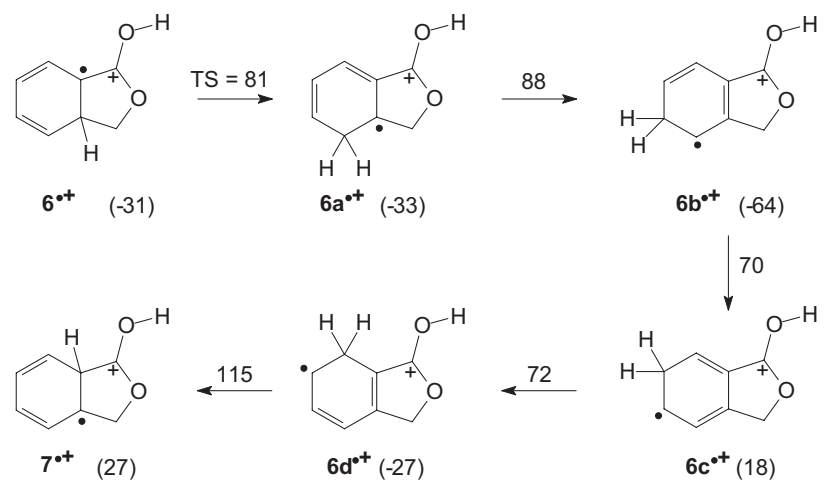

Scheme 8 the hydrogen ring-walk process (see Figure 5 and Scheme 9).

As shown in Scheme 9, carbon-oxygen ring cleavage of the five-membered ring of the intermediate $6^{++}$requires 91 $\mathrm{kJ} \mathrm{mol}^{-1}$. Starting with this intermediate $\mathbf{9}^{-+}$, hydrogen ring-walk within the benzenic ring is allowed to start, the first step being the highest in energy. Once $\mathbf{8}^{+}$is formed, it generates INC1 by cleavage of the $\mathrm{C}-\mathrm{CO}_{2} \mathrm{H}$ bond. All these processes are lower in energy than the isomerization step transforming the conventional radical ion $\mathbf{1}^{++}$into its distonic species $3^{-+}$thus accounting for the observed kinetic isotope effect (vide supra) and accounting also for the predominance of the rearrangement reaction over a simple cleavage reaction in the metastable energy window, the formation of the benzoyl cation plus a methoxyl radical requiring $125 \mathrm{~kJ} \mathrm{~mol}^{-1}$.

As far as the measured kinetic energy releases (KER) are concerned, some additional pieces of information are obtained. Kinetic energy release $\left(T=T^{e}+T^{\#}\right)$ in an ion dissociation is directly related to the reversed activation energy, $\varepsilon_{0}^{\mathrm{R}}$, and $\varepsilon^{\#}$, an excess energy term [10]. The fraction of KER originating from $\varepsilon^{\mathrm{R}}{ }_{0}\left(\mathrm{~T}^{\mathrm{e}}\right)$ is reaction dependent and should be the same for ionized methyl benzoate and ionized phenylacetic acid if dissociation occurs via the same INC1 intermediate (see Figure 5). Nevertheless, the excess energy, $\varepsilon^{\#}$, is statistically distributed over the various oscillators of the decomposing ions and it is theoretically proposed that only a fraction of $\varepsilon^{\#}$ is transformed into KER, namely $\mathrm{T}^{\#}=\varepsilon^{\#} /(0.44 \mathrm{~s})$, where $s$ is the number of oscillators [23].

Coming from ionized methylbenzoate, Figure 5 allows us to calculate the $\varepsilon^{\#}$ term, that is $98\left(\mathrm{TS}_{1 \rightarrow 3}\right)$ minus $52\left(\right.$ INC1) $=46 \mathrm{~kJ} \mathrm{~mol}^{-1}$. Using the previously described equation, $\mathrm{T}^{\#}$ should be $46 /[0.44 \times(3 \times 18-6)]=$ $2.1 \mathrm{~kJ} \mathrm{~mol}^{-1}$ or $20 \mathrm{meV}$.

For the decarboxylation process of ionized phenyl acetic acid, we were not able to find out a transitionstate between $2^{++}$and INC1. Actually, theoretical calculations seem to indicate a continuously endothermic process. In such a case, $\varepsilon^{\#}=0$ and $\mathrm{T}^{\#}$ does not contribute to the KER.

All together, the identical measured KERs are not 


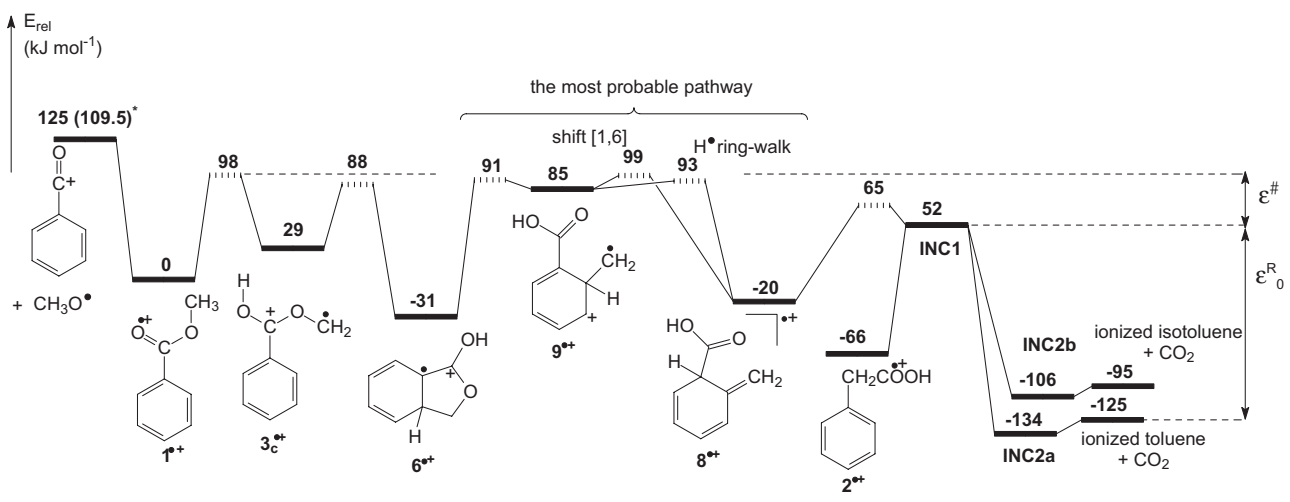

Figure 5. Potential energy surface for intramolecular process occurring at the ortho position followed by $\mathrm{C}-\mathrm{O}$ bond cleavage and the decarboxylation of $2^{\cdot+}$. Relative energies given in $\mathrm{kJ} \mathrm{mol}^{-1}$ were determined from UB3LYP/6-311 ++ G(d,p) + ZPE calculation. *Calculated (this work) and experimental [22] values.

totally in keeping with the proposed potential energy surface. Actually, although we were not able to obtain TS linking INC1 to INC2 $\mathbf{a}, \mathbf{b}$, such TSs are likely to exist and would decrease the $\mathrm{T}^{\#}$ contribution for the decarboxylation of ionized methyl benzoate.

Metastable $H$ loss. It was previously demonstrated by labeling experiments that the leaving hydrogen atom in the metastable process from ionized methyl benzoate specifically arises from the benzene ring. On the other hand, metastable ionized phenylacetic acid does not expel a hydrogen atom.

As shown in Figure 6, the direct cleavage of a $\mathrm{C}-\mathrm{H}$ bond in ionized methyl benzoate requires $395 \mathrm{~kJ} \mathrm{~mol}^{-1}$ to occur. This is by far too high to allow competition with the decarboxylation reaction in the narrow metastable energy window (see Figure 6). However, it was demonstrated by MS3 experiments that the hydrogen atom loss affords protonated phthalide.

Therefore, we proposed that the $\mathrm{H}^{\cdot}$ loss occurs from $6^{+}$ distonic ion obtained on the way to the decarboxylation process (see Figure 5). Starting from $6^{+}$, (see Figure 6) both processes, namely $\mathrm{H}$ and $\mathrm{CO}_{2}$ losses, become competitive since the corresponding TS were calculated 95 and $93 \mathrm{~kJ} \mathrm{~mol}^{-1}$, respectively. The observed primary isotopic effect on the hydrogen atom loss observed for $\mathbf{1}_{d 3}^{++}$is also explained since the rate determining step remains the isomerization from $1^{++}$to $3^{+}$.

It is worthy of note that a hydrogen atom loss $(1 \%)$ is not significantly seen in the case of phenylacetic acid ions $2^{+}$which, quasi-specifically $(96 \%)$, rearrange into $\mathrm{C}_{7} \mathrm{H}_{8}^{+}$ radical cations by carbon dioxide loss. Indeed, decarboxylation of $\mathbf{2}^{+}$does not require intermediates such as $6^{+}$or $7^{+}$, and this fact supports further the mechanisms depicted in Figures 4 and 5.

\section{Conclusions}

Metastable methyl benzoate molecular ions competitively expel carbon dioxide and a hydrogen atom. Whereas the decarboxylation process produces a mixture of two different $\mathrm{C}_{7} \mathrm{H}_{8}$ isomeric ions, namely ionized toluene and isotoluene, the $\mathrm{H}$ atom loss yields protonated phthalide. The mechanisms of these two competitive reactions have been

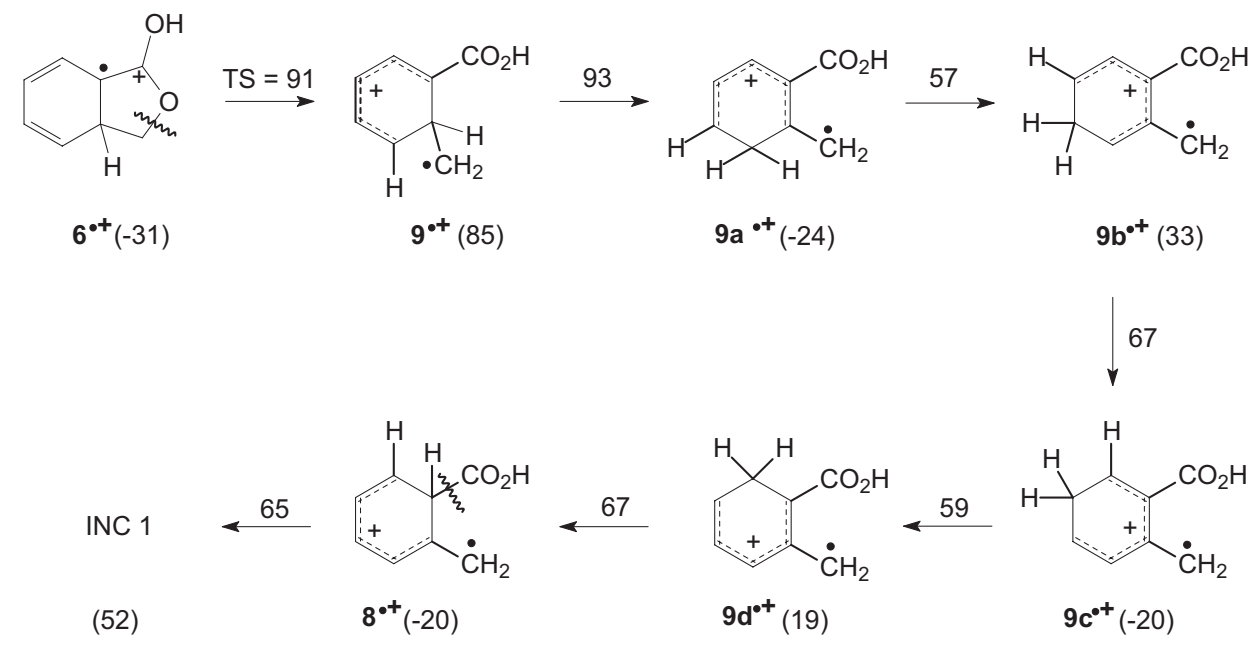

Scheme 9 


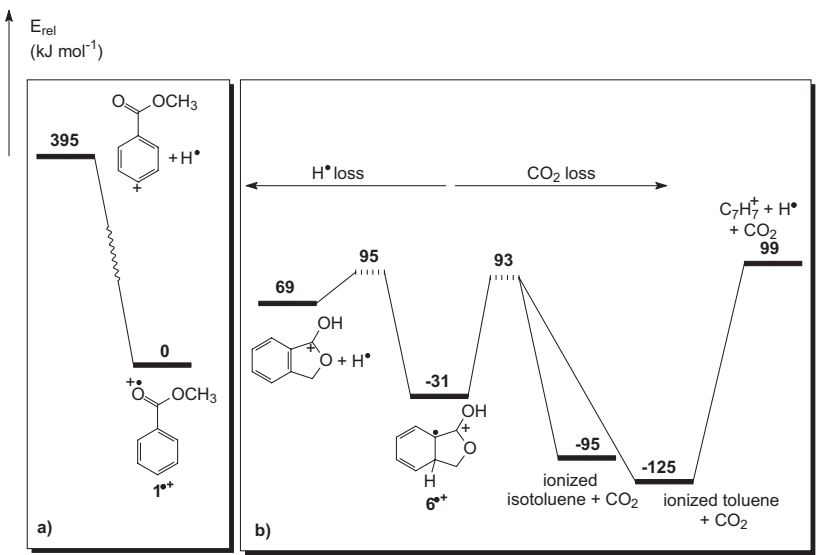

Figure 6. (a) Relative energies for a direct ring $\mathrm{H}$ loss from ionized methyl benzoate $1^{++}$and $(\mathbf{b})$ the competitive $\mathrm{H}^{\cdot}$ and $\mathrm{CO}_{2}$ loss from the key-intermediate $6^{+}$(details for the $\mathrm{CO}_{2}$ loss, see Figure 4).

experimentally and theoretically investigated. The initial step involves a hydrogen migration from the methyl group to the oxygen atom of the carbonyl group $\left(1^{++}\right.$to $3^{+}$) with an energy barrier of $98 \mathrm{~kJ} \mathrm{~mol}^{-1}$, the overall rate-determining step. The $3^{+}$ions then undergo an ortho cyclization into hemiacetal radical cations $6^{+}$. The soobtained key-intermediate proceeds further along two competitive channels, a loss of hydrogen atom readily producing protonated phthalide and a loss of $\mathrm{CO}_{2}$ occurring via ring opening, ring walk hydrogen migrations, and ion-neutral complexes.

Metastable isomeric phenylacetic acid ions also expel carbon dioxide but not a hydrogen atom. The corresponding process also involves ion-neutral complex but since the $6^{+}$intermediate does not appear on the potential energy surface, the absence of the hydrogen atom loss is rationalized.

Finally, it is also worthy of note that the chemistry of metastable ionized enol tautomer of acetanilide (Ph$\left.\mathrm{NHC}(-\mathrm{OH}) \mathrm{CH}_{2}\right)$ presents some interesting analogies with the reaction mechanisms investigated in the present work, the competitive losses of $\mathrm{O}=\mathrm{C}=\mathrm{O}$ and $\mathrm{H}$, being replaced by those of $\mathrm{HN}=\mathrm{C}=\mathrm{O}$ and $\mathrm{H}$ [24].

\section{Acknowledgments}

The Mons laboratory thanks the FNRS, Fonds National de la Recherche Scientifique, for financial support in the acquisition of the AutoSpec 6F mass spectrometer. PG is a Research Associate of the FNRS. The Leuven Group is indebted to the KULeuven Research Council (BOF) and the Concerted Research Action Program (GOA) for continuing support. The referees are also gratefully acknowledged for their constructive comments and suggestions.

\section{References}

1. (a) Kingston, D. G. I.; Bursey, J. T.; Bursey, M. M. Intramolecular hydrogen transfer in mass-spectra 2: McLafferty rearrangement and related reactions. Chem. Rev. 1974, 74(2), 215-242 and references therein; (b) Kingston, D. G. I.; Hobrock, B. W.; Bursey, M. M.; Bursey, J. T. Intramolecular hydrogen transfer in mass-spectra 3: Rearrangement involving loss of small neutral molecules. Chem. Rev. 1975, 75(6), 693-730 and references therein.

2. Hammerum, S. Distonic radical cations in gaseous and condensed phases. Mass Spectrom. Rev. 1988, 7, 123-202 and references therein.

3. Fell, L. M.; Burgers P. C.; Ruttink, P. J. A.; Terlouw, J. K. The decarbonylation of ionized $\beta$-hydroxypyruvic acid: The hydrogenbridged radical cation $\left[\mathrm{CH}_{2}=\mathrm{O}-\mathrm{H}-\mathrm{O}=\mathrm{C}-\mathrm{OH}\right]^{++}$studied by experiment and theory. Can. J. Chem. 1998, 76, 335-349.

4. Audier, H. E.; Milliet, A.; Sozzi, G.; Hammerum, S. $\alpha$-Distonic ions as transient species in the reactions of metastable alkyl benzoate radical cations. Org. Mass Spectrom. 1990, 25, 44-47.

5. Bateman, R. H.; Brown, J.; Lefevere, M.; Flammang, R.; Van Haverbeke, Y. Application in gaseous ion and neutral chemistry using a six-sector mass spectrometer. Int. J. Mass Spectrom. Ion Processes 1992, 115, 205-218.

6. Flammang, R.; Van Haverbeke, Y.; Braybrook, C.; Brown, J. A new hybrid mass spectrometer for the investigation of ion/molecule reactions. Rapid Commun. Mass Spectrom. 1995, 9, 795-799.

7. Frisch, M. J.; Trucks, G. W.; Schlegel, H. B.; Scuseria, G. E.; Robb, M. A.; Cheeseman, J. R.; Montgomery, J. A., Jr.; Vreven, T.; Kudin, K. N.; Burant, J. C.; Millam, J. M.; Iyengar, S. S.; Tomasi, J.; Barone, V.; Mennucci, B.; Cossi, M.; Scalmani, G.; Rega, N.; Petersson, G. A.; Nakatsuji, H.; Hada, M.; Ehara, M.; Toyota, K.; Fukuda, R.; Hasegawa, J.; Ishida, M.; Nakajima, T.; Honda,Y.; Kitao, O.; Nakai, H.; Klene, M.; Li, X.; Knox, J. E.; Hratchian, H. P.; Cross, J. B.; Bakken, V.; Adamo, C.; Jaramillo, J.; Gomperts, R.; Stratmann, R. E.; Yazyev, O.; Austin, A. J.; Cammi, R.; Pomelli, C.; Ochterski, J. W.; Ayala, P. Y.; Morokuma, K.; Voth, G. A.; Salvador, P.; Dannenberg, J. J.; Zakrzewski, V. G.; Dapprich, S.; Daniels, A. D.; Strain, M. C.; Farkas, O.; Malick, D. K.; Rabuck, A. D.; Raghavachari, K.; Foresman, J. B.; Ortiz, J. V.; Cui, Q.; Baboul, A. G.; Clifford, S.; Cioslowski, J.; Stefanov, B. B.; Liu, G.; Liashenko, A.; Piskorz, P.; Komaromi, I.; Martin, R. L.; Fox, D. J.; Keith, T.; Al-Laham, M. A.; Peng, C. Y.; Nanayakkara, A.; Challacombe, M.; Gill, P. M. W.; Johnson, B.; Chen, W.; Wong, M. W.; Gonzalez, C.; and Pople, J. A. Gaussian 03 Rev. B 03; Gaussian, Inc.: Wallingford, CT.

8. McLafferty, F. W.; Turecek, F. Interpretation of mass spectra. University Science Books: Mill Valley, CA, 1993, p 258.

9. Dechamps, N.; Flammang, R.; Gerbaux, P.; Nam, P. C.; Nguyen, M. T. Characterization of a distonic isomer $\mathrm{C}_{6} \mathrm{H}_{5} \mathrm{C}^{+}(\mathrm{OH}) \mathrm{OCH}_{2}$ of methyl benzoate radical cation by associative ion-molecule reactions. Int. J. Mass Spectrom. 2006, 249/250, 484-492.

10. Cooks, R. G.; Beynon, J. H.; Caprioli, R. M.; Lester, G. R. Metastable ions; Elsevier: Amsterdam, 1973; pp 104-122

11. Holmes, J. L.; Terlouw, J. K. The scope of metastable peak observation. Org. Mass Spectrom. 1980, 15, 383-396.

12. Lowry, T.H., Richardson, K.S. Mechanism and Theory in Organic Chemistry. Harper \& Row: New York, 1976, pp 60-67.

13. Flammang, R., Dechamps, N., Gerbaux, P., Nam. P. C., Nguyen, M. T. On the loss of a methyl radical from metastable molecular ions of dimethyl terephthalate; unpublished.

14. Tajima, S.; Tobita, S.; Tsuchiya, T. Fragmentation process of benzenedicarboxylic acid dimethyl esters. Mass Spectrosc. 1986, 34, 99-105.

15. Tajima, S.; Kojima, A.; Sugimura, T.; Nakajima, S.; Takahashi, Y.; Nibbering, N. M. M. On the chemistry following methoxy migration in the metastably decomposing $\left(\mathrm{M}-\mathrm{COOCH}_{3}\right)^{+}$ions $(\mathrm{m} / \mathrm{z} 135)$ from dimethyl phthalate, isophthalate and terephthalate. Int. J. Mass Spectrom. 2003, 228, 891-899.

16. Tajima, S.; Mamada, M.; Nakajima, S.; Takahashi, Y.; Nibbering, N. M. M. Unimolecular gas-phase reactions in diethyl phthalate, isophthalate, and terephthalate upon electron ionization. Aust. J. Chem. 2003, $56,473-479$.

17. Dechamps, N.; Flammang, R.; Gerbaux, P.; Nam, P. C.; Nguyen, M. T. Internal energy effects on charge stripping spectra of $\left[\mathrm{C}_{7} \mathrm{H}_{8}\right]^{++}$and $\left[\mathrm{C}_{5} \mathrm{H}_{6}\right]^{++}$radical cations. Chem. Phys. Lett. 2006, 419, 139-143.

18. Tiecco, M. Radical ipso attack and ipso substitution in aromatic compounds. Acc. Chem. Res. 1980, 13, 51-57.

19. Vogel, P. Chimie Organique, methodes et modeles. De Boeck and Larcier: Paris, Bruxelles, 1997; p 67.

20. Yeo, A. N. H.; Williams, D. H. Rearrangement in the molecular ions of halotoluenes prior to fragmentation in the mass spectrometer. J. Chem. Soc. Chem. Commun. 1970(14), 886-887.

21. Grutzmacher, H. F.; Harting, N. A ring walk of methylene groups in toluene radical cations. An extension of the toluene-cycloheptatriene rearrangement of aromatic radical cations. Theory and experiment. Eur. J. Mass Spectrom. 2003, 9, 327-341.

22. Lias, S. G.; Bartmess, J. E.; Liebman, J. F.; Holmes, J. L.; Levin, R. D.; Mallard, W. G. Gas-phase ion and neutral thermochemistry. J. Phys. Chem. Ref. Data 1988, Supplement no. 1.

23. Haney, M. A.; Franklin, J. L. Correlation of excess energies of electronimpact dissociations with the translational energies of the products. J. Chem. Phys. 1968, 48, 4093-4097.

24. Heydorn, L. N.; Carter, L. M.; Bowen, R. D.; Terlouw, J. K. Reactions of the ionized enol tautomer of acetanilide. Eur. J. Mass Spectrom. 2003, 9, 343-350. 